Authors: R Alberts and J Moolman

\title{
PROTECTING ECOSYSTEMS BY WAY OF BIOLOGICAL CONTROL: CURSORY REFLECTIONS ON THE MAIN REGULATORY INSTRUMENTS FOR BIOLOGICAL CONTROL AGENTS, PRESENT AND FUTURE
}

\section{ISSN 1727-3781}

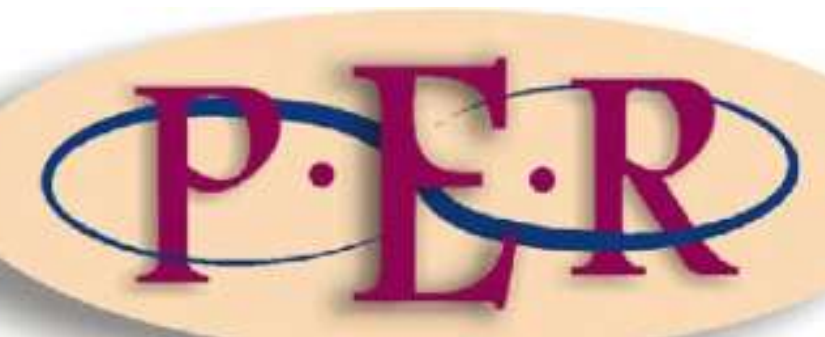

2013 VOLUME 16 No 2 


\section{PROTECTING ECOSYSTEMS BY WAY OF BIOLOGICAL CONTROL: CURSORY REFLECTIONS ON THE MAIN REGULATORY INSTRUMENTS FOR BIOLOGICAL CONTROL AGENTS, PRESENT AND FUTURE}

\section{R Alberts and J Moolman*}

\section{Introduction}

The preceding years have seen an increase in the attention afforded to ecosystems and ecosystem services. Although there are numerous threats to ecosystems and the resultant ecosystem services, alien and invasive plants (AIPs) have been identified as being one of the major causes of ecosystem destruction. In addressing the threat of alien and invasive plants ${ }^{1}$ through the use of various mechanisms, the regulatory framework imposed by legislation is key in ensuring that controlling AIPs ${ }^{2}$ does not in fact do more harm than good. One such control mechanism, which has the potential to do wonders or wreak havoc if not adroitly implemented, is the use of biological control agents. This note will attempt to provide a brief overview of the three main instruments used to regulate biological control agents in South Africa, namely the Conservation of Agricultural Resources Act 43 of 1983 (CARA), the Agricultural Pests Act 36 of 1983 (APA) and the National Environmental Management Biodiversity Act 10 of 2004 (NEM:BA), whilst also considering possible future

* Reece Alberts: BCom LLB, LLM. Environmental Manager, Centre for Environmental Management, North-West University. Email: Reece.Alberts@nwu.ac.za. Jurie Moolman: BSc Environmental Science, Hons Environmental Management, MSc Environmental Sciences. Environmental Manager, Centre for Environmental Management, North-West University (Potchefstroom Campus). Email: Jurie.Moolman@nwu.ac.za.

1 National Environmental Management: Biodiversity Act 10 of 2004 (NEM:BA) defines an alien species as "a species that is not an indigenous species; or an indigenous species translocated" or "intended to be translocated to a place outside its natural distribution range in nature, but not an indigenous species that has extended its natural distribution range by natural means of migration or dispersal without human intervention". The NEM:BA further defines an invasive species as "any species whose establishment and spread outside of its natural distribution range - (a) threatens ecosystems, habitats or other species or has demonstrable potential to threaten ecosystems, habitats or other species; and (b) may result in economic or environmental harm or harm to human health". See McNeely "Invasive Species". This note will focus on the use of Alien and Invasive Species (AIS), for the control of Alien and Invasive Plants (AIP). For the purposes of this note AISs are meant to mean any alien animals, insects or pathogens.

2 For the purpose of this note, Alien and Invasive Species (AIS) will be seen as Alien Invader Plants (AIPs). 
developments on the regulation of biological control agents. This overview will be provided on the back of a brief introduction as to what ecosystems and ecosystems services are, and how biological control agents can aid in addressing threats to them.

\section{An overview of ecosystems and ecosystem services}

Ecosystems can be defined as complex and dynamic combinations of the interaction between the physical and biological spheres of the environment. ${ }^{3}$ They can also be defined as communities of fauna and flora interacting with one another and with their physical environment. ${ }^{4}$ They may operate on a global, long-term scale or on a local, short-term scale. ${ }^{5}$ The result of this interaction between the physical and biological spheres is services that are essential to life on earth. ${ }^{6}$ The phrase "ecosystem services" refers to the goods, services and benefits that biodiversity provides that are vital to human well-being, economic development and social prosperity. $^{7}$

In the recent past, ecosystem services have continually fallen under the spotlight because of the immense monetary value that these services provide. 8 Since the realisation of the worth of ecosystem services (human well-being, financial and social development), a great amount of money and research have gone into

\section{Parry-Davies Enviropedia 92.}

Ecological Society of America 1997 Spring 2. Ecosystems also include physical and chemical components such as the soil, water and nutrients that support the organisms living within these contexts.

5 Parry-Davies Enviropedia 92. Ecosystems are interconnected and are isolated at each level of the ecosystem only to better understand how they work.

6 UNEP Finance Initiative 2008 www.unepfi.org.

7 UN 1992 www.cbd.int/doc; UNEP Finance Initiative 2008 www.unepfi.org. The Convention on Biological Diversity defines biodiversity as "the variability among organisms (being it terrestrial, marine and other aquatic ecosystems) and the ecological complexes of which they are part. It also includes the diversity within and between species and of ecosystems. Ecosystem services or goods include the formation of soil, provision of food, clean air and water, regulation of climate, pollination of crops and natural vegetation, control of agricultural pests, maintenance of biodiversity, mitigation of droughts and floods and protection of streams, river channels and coastal shores from erosion".

8 Parry-Davies Enviropedia 92. It is estimated that ecosystem services are worth between US\$21 -72 trillion a year. 
ecosystem services. ${ }^{9}$ These studies have found that biodiversity, ecosystems and ecosystem services are under great threat. ${ }^{10}$

Alien and invasive plant species were introduced into South Africa more than 1000 years ago via trading routes from other countries in southern Africa. Since the arrival of settlers from Europe these numbers have increased dramatically. ${ }^{11}$ At present, AIPs have established on approximately 10 million hectares in South Africa and it is reported that AIPs consume nearly 330 million meters3 of water annually, or $7 \%$ of the annual run-off. ${ }^{12}$ Water consumption levels by AIPs are estimated to be increasing rapidly and could reach $50 \%$ of the mean annual run-off in the not too distant future. ${ }^{13}$ The aggressive behaviour of the AIPs in their unnatural habitat is a direct threat to the vast wealth of biodiversity in South Africa.14 South Africa is a relatively small country that comprises only $2 \%$ of the total surface of the Earth, but it contains $10 \%$ of the plant species, $7 \%$ of the vertebrates, and is home to three biodiversity hotspots. ${ }^{15}$

$9 \quad$ Egoh et al 2012 Ecosystem Services 71.

10 European Commission 2009 ec.europa.eu. It is projected that $60 \%$ of coral reefs may disappear by 2030 . A total of $11 \%$ of natural habitat could be lost by 2050 . Furthermore, human activities have accelerated the rate of the extinction of species by $50-1000$ times in the past 100 years.

11 McNeely "Invasive Species".

12 ICT Update 2005 ictupdate.cta.int. Both the National Biodiversity Strategy and Action Plan (Department of Environmental Affairs and Tourism National Biodiversity Strategy) as well as the National Biodiversity Framework (GNR 813 in GG 32474 of 3 August 2009) state that woody invasive species, such as the Eucalyptus tree from Australia, use excessively more water than indigenous woody plants, causing disruption in terrestrial and freshwater ecosystems.

13 Van Wilgen et al "Preliminary Assessment" 819-822.

14 Brooks et al 2004 BioScience 680 . Not only do alien and invasive plants pose threats to the species richness of native ecosystems, they also change the bio-fuel properties of the ecosystem, which in turn affects the fire regime characteristics including the frequency, intensity, extent, type and seasonality of fires. Other threats listed by The Water Page (The Water Page 2012 www.thewaterpage.com) that AIPs pose to ecosystems and ecosystem services are the loss of potentially productive land and the loss of grazing potential and livestock production. AIPs reduce the ability to harvest indigenous natural resources, increases the problems associated with flooding, cause erosion, cause the destruction of rivers, cause the siltation of dams and estuaries, create poor water quality and ultimately cause the extinction of indigenous plants and animals. Driver et al National Biodiversity Assessment 2011 raise concerns regarding one of the twelve highlights which came from the National Biodiversity Assessment by stating that the area occupied by AIPs in South Africa doubled between the mid-1990s and 2007, and at least R6.7 billion worth of ecosystem services are lost every year due to AIPs. This amount would be as much as R42 billion without intervention.

15 Le Maitre, O'Farrell and Reyers 2007 SAJS 367-376; Olivier, Myakayaka and Richards "Indigenous Plants" 354. One of these biodiversity hotspots is the fynbos biome. By $198420.5 \%$ of the fynbos biome had been transformed due to the influx of alien and invasive species. This transformation resulted in the local extinction of fynbos species. 


\section{Addressing ecosystem threats: the argument for biological control agents}

Ecosystem services are under pressure from a multitude of threats. ${ }^{16}$ One of the biggest threats to biodiversity, ecosystems and ecosystem services is the introduction and establishment of AIPs.

Several methods have been implemented to control the intrusion of AIPs in South Africa, one of which is the use of Alien and Invasive Species (AIS) as biological control agents. ${ }^{17}$ Biological control has become one of the most highly favoured methods in the fight against AIPs due to the relatively low input cost and high success rate of the practice. ${ }^{18}$ It is also widely argued that biological control is the only sustainable method to control the spread of AIPs over a long period of time. ${ }^{19}$ This practice has been accepted and implemented as part of the management programme of AIPs in the Kruger National Park, due to the failure of other methods to control unwanted invaders. ${ }^{20}$

16 UNEP Finance Initiative 2008 www.unepfi.org. Threats to ecosystem services include: the destruction of habitat for the conversion for urban, industrial and agricultural development; soil, water and air pollution; climate change and over exploitation (for example, unsustainable fishery activities).

17 Anon Date Unknown www.unep.org. The three primary methods of controlling AIPs are physical control (which may include the uprooting of plants, sawing, slashing, axing, bulldozing and controlled burning), chemical control (which usually complements physical control) and biological control (where the natural enemy of the AIPs is released to control the vigour, reproductive capacity and effect of AIPs.)

18 In the paper, Risks of Species Introduced for Biological Control, Simberloff and Stiling (Simberloff and Stiling 1996 Biological Conservation) describe two types of biological control. Biological control can be termed either "neoclassical biological control", where non-indigenous enemies are introduced to attack native species or, as in this case "classical biological control", which entails the introduction of enemies (animals, insects or pathogens) of non-indigenous pests (Moran, Hoffmann and Zimmerman 2005 Frontiers of Ecology and Environment 77-83). Since 1913, 63 biological control agents have been released on 44 IAPs, with 11 AIPs sustainably controlled by the biological control agents (Department of Water Affairs 2013 www.dwaf.gov.za). It is estimated that it costs approximately R1 480/ha for the chemical control of water hyacinth, compared with approximately R310/ha for bio-control. From 1986 until 1999 more than R6 million was spent to reduce the vigour of water hyacinth with chemical control. This amount would have been drastically lower had biological control been used. 
To date, there are no reports of damaged being caused to any native plant species in South Africa by the introduction of such agents. ${ }^{21}$ In fact, there are several success stories of biological control agents curbing the vigour of AIPs. ${ }^{22}$ Since the determined efforts to control AIPs started more than 90 years ago, biological control has played a crucial role in the management of AIPs in South Africa and has gained cumulative support from government ${ }^{23}$

\section{The legal framework for using biological control agents}

The use of biological control agents in the combating of AIPs in itself often entails the introduction of AISs into an ecosystem. In understanding the legal framework applicable to the use of biological control agents such as AISs to combat AIPs, this note will focus predominantly on three pieces of legislation, namely the CARA, the NEM:BA, and the APA. The note will be structured around the following discussions, namely the legal requirements for the control of AISs and AIPs and specific regulatory measures for biological control agents as a method of control for AIPs, before finally reflecting on the challenges and possible future challenges. ${ }^{24}$

21 Moran, Hoffmann and Zimmerman 2005 Frontiers of Ecology and Environment 77-83; Simberloff and Stiling 1996 Biological Conservation highlight the risks associated with the release of biological control agents. One such risk is that the biological control agent introduced may not be host specific and may attack native non-target species.

22 Zimmerman and Moran 1991 Agriculture, Ecosystems and Environment 29-35. The cochineal insect, Dactylopius opuntiae (Cockerell), was introduced into South Africa to assist in the control of the prickly pear Optunia ficus-indica (L.) Miller, which infested approximately 1 million hectares. The cochineal insect reduced the infestation of the prickly pear to less than 100000 ha.

23 Moran, Hoffmann and Zimmerman 2005 Frontiers of Ecology and Environment 77-83.

24 The authors recognise that the legal framework governing alien and invasive species is complex and multi-faceted. Governance is further fragmented between National, Provincial and Local Government spheres and amongst several government departments within the same sphere. The purpose of this note is not to provide an in-depth discussion of this legal framework, but rather to provide a cursory reflection on the main tenets of the framework as it regulates the introduction of biological control agents. Acts not discussed in this note which form part of the legal framework regulating alien and invasive species include inter alia the National Water Act 36 of 1998, the National Forests Act 84 of 1998 and the National Veld and Forest Fire Act 101 of 1989. A comprehensive and exhaustive discussion on the legal framework regulating alien and invasive species is adroitly provided by AR Paterson. Refer to Paterson 2006 PER 152-207. 


\subsection{The regulatory control of alien and invasive species and plants in South Africa}

CARA, the APA and NEM:BA all contain measures for the regulatory control of AISs and AIPs in South Africa. CARA, through the Conservation of Agricultural Resources Act Regulations, ${ }^{25}$ deals with several issues relating to the control of weeds and invasive plants. $^{26}$ Regulations 15A, 15B and 15C which deal with the control of category 1, 2 and 3 plants, set out the permitted activities which may be undertaken with each category of plants. ${ }^{27}$ Regulation 15 furthermore provides for the

25 GN R1048 in GG 9238 of 25 May 1984.

26 CARA defines a "weed" as being: "any kind of plant which has under section 2(3) been declared a weed, and includes the seed of such plant and any vegetative part of such plant which reproduces itself asexually". An invader plant is defined as being "a kind of plant which has under section 2(3) been declared an invader plant, and includes the seed of such plant and any vegetative part of such plant which reproduces itself asexually". Section 2(3) of CARA states that the minister may by regulation declare any plant to be a weed or an invader plant for the purposes of this Act, either throughout the Republic or in one or more areas therein. It is contended that the lack of a substantive definition of "weedv and "invader plantv has led to some invading alien plants as being categorised differently in some of the provinces. An example is the Silver Wattle (Acacia dealbata), which is classified as being a category 1 plant in the Western Cape, but a category 2 plant in the rest of the country.

27 In terms of reg $15 \mathrm{~A}(1)$ of CARA, category 1 plants may not occur on any land or inland water surface other than in biological control reserves. Reg 15A(2) states that a land user shall control any category 1 plants that occur on any land or inland water surface by means of the methods prescribed in reg $15 \mathrm{E}$. No person shall, except in or for purposes of a biological control reserveestablish, plant, maintain, multiply or propagate category 1 plants; import or sell propagating material of category 1 plants or any category 1 plants; acquire propagating material of category 1 plants or any category 1 plants. In terms of reg 15B(1) category 2 plants may not occur on any land or inland water surface other than a demarcated area or a biological control reserve. The executive officer may on application in writing demarcate an area as an area where category 2 plants may occur, be established and be maintained. Furthermore an area in respect of which a water use licence for stream flow reduction activities has been issued in terms of $s 36$ of the National Water Act 36 of 1998 shall be deemed to be a demarcated area. Reg 15B(2) states that the executive officer shall demarcate an area for the occurrence, establishment and maintenance of category 2 plants only if the category 2 plants in the area are cultivated under controlled circumstances; and the land user concerned has been authorised to use water in terms of the National Water Act 36 of 1998); the category 2 plants or products of category 2 plants in the area are demonstrated to primarily serve a commercial purpose, use as a woodlot, shelter belt, building material, animal fodder, soil stabilisation, medicinal or other beneficial function that the executive officer may approve and all reasonable steps are taken to curtail the spreading of propagating material of the category 2 plants outside the demarcated areas. Reg 15B(4) continues to state that when an area is demarcated for the occurrence, establishment and maintenance of category 2 plants the executive officer may impose such additional conditions as may reasonably be deemed necessary to keep the category 2 plants in the area in check. Reg $15 \mathrm{~B}$ states furthermore that no person shall sell propagating material of category 2 plants or any category 2 plants to another person unless such other person is a land user of a demarcated area or of a biological control reserve or acquire propagating material of category 2 plants or any category 2 plants unless such material or such plants are intended for use in a demarcated area or in a biological control reserve; propagating material of category 2 plants or category 2 plants 
measures applicable to each of the categories of plants as identified. These measures are contained in regulation $15 \mathrm{E} .{ }^{28}$ An important provision in regulation $15 \mathrm{E}$ is the inclusion of regulation $15 \mathrm{E}(5)$, which dictates that any action taken to control category 1, 2 and 3 plants shall be executed with caution and in a manner that will cause the least possible damage to the environment. This implied duty of care is binding on any landowner undertaking control measures.

The APA which has as its main aim the prevention and combating of agricultural pests contains several provisions relating to the importation of controlled goods into the country. ${ }^{29}$ Although not making direct reference to AISs and AIPs, the APA regulates the importation of alien and potentially invasive plants, pathogens and

shall only be imported or sold in accordance with the provisions of the Plant Improvement Act, 1976 (Act No. 53 of 1976), the Agricultural Pests Act, 1983 (Act No. 36 of 1983) and the environment conservation regulations. A land user shall control any category 2 plants that occur on any land or inland water surface in contravention of the provisions of sub-regulation (1) by means of the methods prescribed in regulation $15 \mathrm{E}$. Unless authorised thereto in terms of the National Water Act 36 of 1998, no land user shall allow category 2 plants to occur within 30 meters of the 1:50 year flood line of a river, stream, spring, natural channel in which water flows regularly or intermittently, lake, dam or wetland. The executive officer may, on good cause shown in writing by the land user, grant written exemption from compliance with one or more of the requirements of sub-regulations (1), (3), (5), (6), (8) and (9) on such conditions as the executive officer may determine in each case. Category 3 plants are dealt with by reg $15 \mathrm{C}$ which dictates that Category 3 plants shall not occur on any land or inland water surface other than in a biological control reserve. Reg 15(C)3 dictates that no land user shall allow category 3 plants to occur within 30 meters of the 1:50 year flood line of a river, stream, spring, natural channel in which water flows regularly or intermittently, lake, dam or wetland. Furthermore a land user must take all reasonable steps to curtail the spreading of propagating material of category 3 plants. Reg $15 C(4)$ states that no person shall, except in or for the purposes of a biological control reserve (a) plant, establish, maintain, multiply or propagate category 3 plants; (b) import or sell propagating material of category 3 plants or any category 3 plants; or (c) acquire propagating material of category 3 plants or any category 3 plants. Like the regulations pertaining to category 2 plants, reg $15 C(5)$ provides that the executive officer may, on good cause shown in writing by the land user, grant written exemption from compliance with one or more of the requirements of sub-regulations (1), (3) and (4) on such conditions as the executive officer may determine in each case.

28 Methods of control as listed in reg $15 \mathrm{E}(1)$ include inter alia: uprooting, felling, cutting or burning; Biological Control Agents; treatment with a weed killer that is registered for use in connection with such plants in accordance with the directions for the use of such a weed killer; biological control carried out in accordance with the stipulations of the APA, the Environment Conservation Act 73 of 1989 and any other applicable legislation; any other method of treatment recognised by the executive officer that has as its object the control of the plants concerned, subject to the provisions of sub-regulation (4); a combination of one or more of the methods prescribed in paragraphs (a), (b), (c), and (d) save that biological control reserves and areas where biological control agents are effective shall not be disturbed by other control methods to the extent that the agents are destroyed or become ineffective.

29 In terms of s 3(1)(a)-(b), no person shall import into the republic any plant, pathogen, insect, exotic animal, growth medium, infectious thing, honey, beeswax or used apiary equipment or anything determined by the Minister by notice in the gazette except on the authority of a permit. 
insects, with the Department of Agriculture, Forestry and Fisheries (DAFF) being responsible for the implementation of both CARA and the APA.

NEM:BA arguably contains the most substantive provisions relating to AIPs and AISs. Chapter 5 of NEM:BA deals specifically with species and organisms posing potential threats to biodiversity. NEM:BA chapter 5 makes a distinction between "alien species" $^{130}$ and "invasive species" ${ }^{11}$ with differing levels of regulation for each. Through the workings of NEM:BA, alien species are regulated via three main mechanisms as provided by the Act. These are briefly: (a) The issuing of a permit should a person wish to undertake a certain defined restricted activity regarding a specimen of alien and invasive species. ${ }^{32}$ Such a permit may be issued only after a prescribed assessment of the risks and potential impacts on biodiversity is carried out. NEM:BA furthermore affords for the Minister to publish a list of alien species in respect of which restricted activities are prohibited. (b) NEM:BA also contains a duty of care applicable to any person who wishes to undertake a restricted activity involving any alien species, whether they are so permitted or not. ${ }^{33}$ This duty of care dictates that persons undertaking restricted activities must do so in accordance with the permit as issued for such a restricted activity, ${ }^{34}$ and that they must take all the steps required to prevent or minimise harm to biodiversity. ${ }^{35}$ (c) Section 69 continues to provide the competent authority with powers to issue directives should a person fail to comply with the provision of the duty of care. ${ }^{36}$ Should such a person fail to comply with a directive, the competent authority may take the requisite

$30 \quad$ NEM:BA in section 1 defines an alien species as being:

(a) a species that is not an indigenous species; or

(b) an indigenous species translocated or intended to be translocated to a place outside its natural distribution range in nature, but not an indigenous species that has extended its natural distribution range by natural means of migration or dispersal without human intervention.

31 NEM:BA in section 1 defines an invasive species as being any species whose establishment and spread outside of its natural distribution range- (a) threatens ecosystems, habitats or other species or has the demonstrable potential to threaten ecosystems, habitats or other species; and (b) may result in economic or environmental harm or harm to human health. Section 65(1) of NEM:BA. NEM:BA defines restricted activities as being inter alia importing, exporting, growing, propagating, conveying or having alien species in a person's possession.

33 Section 69 of NEM:BA.

34 Section 69(1)(a) of NEM:BA. See also $n 33$ above.

35 Section $69(1)(b)$ of NEM:BA.

36 Section $69(2)$ of NEM:BA. 
actions and claim the costs associated with implementing the directive. ${ }^{37}$ Section 69(4) of NEM:BA states specifically that should an alien species establish itself in nature as an invasive species because of the actions of a specific person, a competent authority may hold the person liable for any costs incurred in the control and eradication of the species.

NEM:BA regulates invasive species within Chapter 2 part 5. Invasive species are subject to stricter regulation than those deemed to be alien, as stated above. In accordance with section 70 the Minister may publish a list of invasive species, but to date such a list has not yet been finalised and thus the provisions regulating invasive species will not be of force. ${ }^{38}$ No person may undertake a restricted39 activity involving a specimen of a listed invasive species unless such a person is in possession of the requisite permit as prescribed. ${ }^{40}$ Mirroring the provision pertaining to alien species, such a permit may be issued only once the prescribed assessment of risks and potential impacts on biodiversity had been completed. As with alien species there are no substantive provisions within NEM:BA giving guidance as to how these risk assessments should be conducted, like the provisions regulating alien species, a duty of care is imposed with regards to invasive species, which is applicable to both permit holders and landowners. ${ }^{41}$

NEM:BA furthermore, through the workings of section 75, imposes a range of obligations on the manner in which listed invasive species can be controlled and eradicated. ${ }^{42}$ Among the prescribed control measures section $75(2)$ states that any

37 Section 69(3)(a)-(b) of NEM:BA.

38 Provincial MECS may also publish provincial lists of invasive species. A draft national list of invasive species in terms of $s 70$ of NEM:BA was published in GNR 250 in GG 32090 of 3 April 2009.

39 See $\mathrm{n} 32$ above.

40 Section 71(1) of NEM:BA.

41 The duty of care as it pertains to invasive species appears to be more comprehensive than that applying to alien species. S 73(2) of NEM:BA requires that a person who is the owner of land on which a listed invasive species occurs must notify the relevant competent authority, in writing, of the listed invasive species occurring on the land. Such a landowner must furthermore take steps to eradicate the listed invasive species and to prevent it from spreading, and must take all the steps required to prevent or minimise harm to biodiversity.

42 Section 75 (1)-(5) of NEM:BA sates the following:

Control and eradication of a listed invasive species must be carried out by means of methods that are appropriate for the species concerned and the environment in which it occurs. 
action taken to control and eradicate a listed invasive species must be executed in a manner that may cause the least possible harm to biodiversity and damage to the environment. This provision thus places a duty on persons implementing control methods to ensure that such methods will not have a more detrimental impact on the environment than the invasive species which is to be eradicated. The issuing of permits by the relevant authorities to persons wishing to undertake restricted activities is subject to the correct procedures being followed by the applicant to assess the risk and potential impacts of the restricted activity, that the relevant species has been found to have negligible or no invasive potential, that the benefits of allowing the activity to continue are greater than the potential costs associated with preventing or remedying any resultant damage to the environment or biodiversity, and lastly that the relevant authority is satisfied that adequate measures have been taken by the applicant to prevent the spread of the alien or invasive species. ${ }^{43}$ Paterson contends, however, that no clear guidelines are prescribed as to what may constitute adequate procedures or measures as they relate to the content of section 91 of NEM:BA discussed above, and that one would hope to see a prescription of the detail by way of regulation. ${ }^{44}$ Such detail has been provided by way of draft regulations, but these are not yet enforceable. This, combined with the fact that NEM:BA provides very little guidance on the duty of care, the actual control methods to be adopted for the management of alien and invasive species, as well as the exact procedures to be followed when undertaking a restricted activity, may result in many questions being left unanswered.

As alluded to above, many of the more detailed provisions relating to Alien and Invasive species as contained in NEM:BA may be found in the Draft Alien and

Any action taken to control and eradicate a listed invasive species must be executed with caution and in a manner that may cause the least possible harm to biodiversity and damage to the environment. The methods employed to control and eradicate a listed invasive species must also be directed at the offspring, propagating material and re-growth of such invasive species in order to prevent such species from producing offspring, forming seed, regenerating or re-establishing itself in any manner. The Minister must ensure the coordination and implementation of programmes for the prevention, control or eradication of invasive species.

The Minister may establish an entity consisting of public servants to coordinate and implement programmes for the prevention, control or eradication of invasive species.

43 Section 91 of NEM:BA.

44 Paterson 2006 PER 152-207. 
Invasive Species Regulations. ${ }^{45}$ The purpose of the proposed regulations are to prevent the unauthorised introduction and spread of alien species to ecosystems and habitats where they do not naturally occur, ${ }^{46}$ to manage and control invasive species to prevent or minimise harm to the environment and to biological diversity in particular, ${ }^{47}$ and where possible and appropriate, eradicate invasive species that may cause such harm. ${ }^{48}$ The draft regulations contain substantive provisions fleshing out the requirements of NEM:BA in so far as they relate to alien and invasive species. Chapter 5 of the alien and invasive species regulations deals with restrictions as they apply to activities relating to alien and invasive species. Regulation 21 sets out the lists of alien species, ${ }^{49}$ prohibited alien species, ${ }^{50}$ and invasive species, ${ }^{51}$ whilst regulation 22 sets out the restricted activities as they pertain to alien and listed invasive species. ${ }^{52}$ Regulation 24 sets out a general restriction of importation in the absence of a permit. ${ }^{53}$ In terms of this regulation, any person thus intending to import an alien species for example in the use of bio control, will have to be issued with the requisite permit to do so. In addition, the actual release of the species into the environment is also subject to regulation 24 .

45 GNR 247 in GG 32090 of 3 April 2009. The publication of a newer set of draft alien and invasive species regulations appears to be imminent, with the Chairperson of the Interim Joint Committee on the Scrutiny of Delegated Legislation being provided with a legal opinion on the "Alien and Invasive Species Regulations, 2012" on the 30th of April 2013. To date the 2012 regulations are not publicly available, and for this reason the note will focus on the 2009 regulations. Regulation 2(a) of the Draft Alien and Invasive Species Regulations.

Regulation 2(b) of the Draft Alien and Invasive Species Regulations.

Regulation 2(c) of the Draft Alien and Invasive Species Regulations.

List 1 in GNR 248 in GG 32090 of 3 April 2009.

List 2 in GNR 249 in GG 32090 of 3 April 2009.

List 3 in GNR 250 in GG 32090 of 3 April 2009.

Regulation 22(1)(a)-(c) of the Draft Alien and Invasive Species Regulations states that in addition to those activities defined in NEM:BA as being restricted activities, the following activities are prescribed as restricted activities: allowing any specimen of an alien or listed invasive species to grow, breed or multiply; allowing the movement or spread of a specimen of an alien or listed invasive species; and releasing a specimen of an alien or listed species.

Regulation 24(1)-(3) of the Draft Alien and Invasive Species Regulations states the following: A person may not import into the republic a specimen of any species, including exempted species, unless authorised to do so by a permit. A person may furthermore not release a specimen of a new alien species imported in the Republic in terms of reg 24(1) unless authorised to do so by a permit. Any application for importation of a specimen of a species into the Republic shall require the written consent of the Head of Department of the province to which the specimen is to be transported or in which it is to be released. 
Regulation 25 allows for certain species to be exempt from permitting should a restricted activity be undertaken with that particular species. ${ }^{54}$ This exemption is not applicable, however, in so far as the activity with the species relates to any of those listed in regulation 24 as discussed above. ${ }^{55}$ Regulation 26 confirms that no person may import or undertake any other restricted activity involving a species which is deemed to be a prohibited alien. Such a species may, however, be imported for biocontrol purposes pursuant to regulation 62 , which is discussed below. ${ }^{56}$ Regulation 27 deals with species requiring compulsory control, and states that no person may undertake a restricted activity as listed, involving a specimen which is found in List 3 as an invasive species, thus effectively excluding such species from being used as possible biological control agents. ${ }^{57}$ Regulation $27(2)$ states further that any person who has under his or her control such a specimen requiring compulsory control and for which no permit has been issued is bound to notify a competent authority of such an occurrence in writing. The workings of regulation 62 as discussed below, however, allow for a relaxation in these provisions in so far as regulation 62 deals with specimens being used under the auspices of biological control.

Regulation 28 contains the provisions relating to invasive species that are controlled by invasive species management programmes, and sets out a range of restricted activities relating to invasive species as contained in list 3 . These restricted activities include inter alia activities relating to the importing, buying, conveying, selling and receiving of such species. ${ }^{58}$ Regulation 29 contains similar provisions regarding restricted activities in so far as they relate to listed invasive species as controlled by

54 Regulation 25(1) of the Draft Alien and Invasive Species Regulations.

55 See $\mathrm{n} 60$.

56 See $\mathrm{p} 17$ below.

57 Regulation 27(1)(a)-(i) of the Draft Alien and Invasive Species Regulations states that a person may not, without a permit, undertake any of the following restricted activities involving a specimen of a species listed in List 3 as an invasive species requiring compulsory control: importing a specimen into the Republic, including introducing it from the sea; possessing or exercising physical control over a specimen; growing a specimen, or allowing it to grow, breed or multiply; breeding or in any other way propagating a specimen or causing it to multiply; conveying, moving or otherwise translocating a specimen; selling or otherwise trading in, giving, donating or disposing of a specimen; buying, receiving, accepting as a gift, or in any way acquiring a specimen; or conducting any other activity prescribed in reg 23 or 24 involving a specimen.

Regulation 28(1)(a)-(g) of the Draft Alien and Invasive Species Regulations. 
area, ${ }^{59}$ whilst regulation 31 lists restricted activities that may not be undertaken with listed species as controlled by an activity. ${ }^{60}$ Regulations 28, 29 and 31 allow for the restricted activities to be conducted without a permit in certain circumstances. An indepth discussion of these regulations would be trite given the focus of the note and the workings of regulation 62 as discussed below, which allows for certain restricted activities to be undertaken notwithstanding the provisions of regulations 28,29 and 30 for the purposes of biological control agents.

Chapter 6 of the regulations deals with risk assessments pertaining to AIS. Regulation 35 dictates inter alia in sub regulation (d) that a risk assessment must be undertaken prior to issuing a permit to undertake any other restricted activity involving a specimen of a listed invasive species other than those listed in regulation 35(1). ${ }^{61}$ The general requirements for risk assessments to be conducted in accordance with the regulations are contained in regulation 36 , which states that a risk assessment must consist of ${ }^{62}$ an initial risk assessment ${ }^{63}$ and, if the initial risk assessment does not clearly demonstrate that there would be no significant risk of invasion by the species to which the application relates, a comprehensive risk assessment. ${ }^{64}$ Furthermore the draft regulations provide for a framework with which all risk assessments must comply. ${ }^{65}$ Regulation 37 deals specifically with risk assessments for import permits, and sets out the relevant factors that such an assessment must consider. Any person wanting to import any species as contemplated in regulation 24 would have to comply with these provisions. ${ }^{66}$ Such a risk assessment must consider the provisions contained in regulation 37(1)(a)(i)-(iii), which relate to risks and potential impacts directly attributed to the species, as well as the risk of the specimen serving as a vector through which other species may be

59 Regulation 29(1)(a)-(i) of the Draft Alien and Invasive Species Regulations.

60 Regulation 31(1)(a)-(i) of the Draft Alien and Invasive Species Regulations.

61 Regulation 35(1)(a)-(c) of the Draft Alien and Invasive Species Regulations states that a risk assessment must be conducted prior to carrying out an activity prescribed in terms of reg 23, importing into the republic a specimen of any species in terms of reg 24 , demarcating an area in terms of reg 30.

62 Regulation 36(a) of the Draft Alien and Invasive Species Regulations.

63 Regulation 36(a)(i) of the Draft Alien and Invasive Species Regulations..

64 Regulation 36(a)(ii) of the Draft Alien and Invasive Species Regulations.

65 Regulation 36(b) and addendum A of the Draft Alien and Invasive Species Regulations. See also reg 41.

66 See $\mathrm{n} 62$ above. 
introduced to the republic and the risk that the method by which the specimen is to be introduced or the restricted activity carried out could serve as the pathway through which other specimens might be introduced.

Regulation 38(1) sets out the requirements as they relates to the risk assessment framework, and requires that the Institute ${ }^{67}$ within one year of the date, on which the regulations come into effect, is to develop and publish guidelines for carrying out the risk assessment. However, pending the publication of the guidelines, regulation 38 (2) defines the minimum considerations to be included in a risk assessment. These requirements can be broadly listed as being the disclosure of information regarding the relevant species, ${ }^{68}$ information regarding the restricted activity in respect of which the permit is sought, ${ }^{69}$ information regarding the receiving environment, ${ }^{70}$ and any other information that the issuing authority may determine. ${ }^{71}$ Any risk assessments that are conducted in terms of the regulations must identify the following, namely: (a) the probability that the species will naturalise in the area where the restricted activity is undertaken or elsewhere in the Republic $^{72}$ (b) the probable impact of the species on the biodiversity and sustainable use of natural resources of the area in which the restricted activity is to be undertaken as well as elsewhere in the Republic; $^{73}$ (c) the risks and potential impacts on biodiversity posed by the species, ${ }^{74}$ (d) the risk of the specimen serving as a vector through which specimens of other alien species may be introduced, ${ }^{75}$ (e) the risks of the method by which a specimen is to be introduced or the restricted

67 The draft alien and invasive species regulations fail to provide a definition for what is to be considered as an "institute", but NEM:BA s 1 defines an "institute" as the South African National Biodiversity Institute established in terms of $s$ 10 of NEM:BA. Regulation 38(1)(a) of the Draft Alien and Invasive Species Regulations. Such information may include inter alia the taxonomy of the species, the originating environment of the species, the persistence attributes of the species, and its invasive tendencies. Regulation 38(1)(b) of the Draft Alien and Invasive Species Regulations. Such information may include inter alia the nature of the restricted activity, the reason for the restricted activity, the location of the restricted activity and the number of the species involved.

70 Regulation 38(1)(c) of the Draft Alien and Invasive Species Regulations. Such information may include inter alia climate match, habitat, the presence of natural enemies, predators and competitors, and the presence of potentially reproductive compatible species. Regulation 38(1)(d) of the Draft Alien and Invasive Species Regulations.

Regulation 38(3)(a) of the Draft Alien and Invasive Species Regulations.

Regulation 38(3)(b)(i)-(ii) of the Draft Alien and Invasive Species Regulations.

Regulation 38(3)(c) of the Draft Alien and Invasive Species Regulations.

Regulation 38(3)(d) of the Draft Alien and Invasive Species Regulations. 
activity carried out serving as a pathway through which specimens of other alien species may be introduced, and; (f) any other measures necessary to manage the associated risks. ${ }^{76}$

Based on the aforementioned provisions of regulation 38(1)-(3), the risk assessment must consider several factors. These can be listed as follows: ${ }^{77}$

- The likelihood of the risk being realised;

- The severity of the risks and consequences of the realisation of the risks for other species, habitats and ecosystems;

- The potential costs associated with the control or eradication of the species to minimise harm to biodiversity;

- $\quad$ Options for minimising the potential risk;

- $\quad$ Management of the potential risk.

The regulations proceed to set out the requirements for a risk assessment facilitator $^{78}$ as well as the costs associated with risk assessments ${ }^{79}$ and the format of the risk assessment reports. ${ }^{80}$ The requirements for a risk assessment facilitator are a commendable measure and will hopefully bring uniformity and consistency to the practice of risk assessment.

A brief overview of the regulatory provisions pertaining to AISs and AIPs as contained within the CARA, APA and NEM:BA has been provided in the above discussion. As it is presumed that almost all biological control agents are alien species, such a discussion is warranted so as to gain an oversight of the regulation of alien species. The most substantive of these regulations are contained within NEM: BA and the draft Alien and Invasive Species Regulations. CARA, the APA and NEM: BA all provide for the restriction of certain activities relating to AISs and AIPs, with several regulatory methods being provided. Common to all three pieces of

Regulation 38(3)(e)-(f) of the Draft Alien and Invasive Species Regulations.

Regulation 38(4)(a)-(e) of the Draft Alien and Invasive Species Regulations.

Regulation 39 of the Draft Alien and Invasive Species Regulations.

Regulation 40 of the Draft Alien and Invasive Species Regulations.

Regulation 42 of the Draft Alien and Invasive Species Regulations. 
legislation is the permitting of certain activities relating to AISs and AIPs, with CARA, the APA and NEM:BA making provision for such permits to be issued in certain circumstances. It must also be noted that both CARA and NEM:BA provide for the relaxation of regulation in so far as certain activities relate to the biological control agents or biological control reserves, whilst a common inclusion in both the CARA and NEM:BA is the duty of care in general relating to AISs and AIPs, which also applies to the introduction and use of biological control agents. The above discussion should serve to highlight some of the more pertinent provisions relating to the regulation of alien and invasive species, and should thus provide an overview of the broader regulatory framework as it applies to biological control agents in so far as they are alien species. The likelihood of any biological control agent being released should it be deemed to be invasive is very low, but the provisions relating to invasive species were discussed for the sake of completeness.

The focus of this note being upon the regulatory framework as applicable to biological control agents, the discussion will now turn to the legal provisions as contained within the above, relating specifically to the introduction and use of biological agents in the control of AIPs.

\subsection{Legal provisions relating to biological control in combating AIPs}

Although the introduction of biological control agents is often tantamount to the introduction of alien species, and thus by implication subject to the general legislative provisions relating to AISs, specific mention is also made in the legislation to biological control agents.

CARA's regulations $15 \mathrm{~A}, 15 \mathrm{~B}$ and $15 \mathrm{C}$, which deal with the control of category 1,2 and 3 plants, all make mention of biological control reserves, ${ }^{81}$ whilst regulation $15 \mathrm{D}$ deals with the designation of such biological control reserves and sets out the

81 A "biological control reserve" means an area designated by the executive officer in terms of reg $15 \mathrm{D}$ of the regulations for the breeding of biological control agents (Conservation of Agricultural Resources Regulations in GNR 1048 in GG 9238 of 25 May 1984). 
provisions under which the executive officer may designate such a control reserve. ${ }^{82}$ Regulation 15 furthermore provides for the measures applicable to each of the categories of plants as identified. These measures are contained in regulation $15 \mathrm{E}$, which lists amongst others the use of biological control ${ }^{83}$ carried out in accordance inter alia with the stipulations of the APA and any other applicable legislation. ${ }^{84}$ The duty of care provisions as contained within regulation $15 \mathrm{E}$ also apply to the use of biological control agents, and dictate that biological control shall be executed with caution and in a manner that will cause the least possible damage to the environment. CARA thus allows for the use of biological control agents within its framework for the control of category one, two and three plants. It provides that despite the regulations pertaining to such categories, a person may inter alia keep, maintain, propagate and transport such alien and invasive plants under the auspices of a biological control reserve, where biological control agents are bred. But CARA does not provide clearly defined standards for dealing with the intentional introduction of AISs as may be the case with bio-control, and furthermore makes provision only for the imposition of penalties on non-compliance with the regulations controlling the further spread of invading alien plants, along with the provisions of regulation $15 \mathrm{E}(5)$, which require that the least possible environmental damage be perpetrated when biological control is used. It may be argued that DAFF makes use

82 Regulation $15 \mathrm{D}(2)(\mathrm{a})$-(c) of the Conservation of Agricultural Resources Regulations states that the executive officer shall designate an area as a biological control reserve only if - the area concerned is used for the breeding of biological control agents by a biological control expert; and no other measures that may destroy or render the biological control ineffective are applied in that area; and the area concerned serves as a refuge from where biological control agents can move or be distributed to other infestations of category 1, 2 and 3 plants.

83 Biological control is defined as being "the use of natural enemies of category 1, 2 and 3 plants to control such plants". A vbiological control agent" means a natural enemy of category 1, 2 or 3 plants that is used to control such plants; "biological control expert" means an academic or research institute or an academic or research organisation established by legislation which, or a person associated with or in the employment of such an institute or organisation who, practises and researches biological control of category 1, 2 and 3 plants.

84 Other methods of control as listed in reg $15 \mathrm{E}(1)$ of the Conservation of Agricultural Resources Regulations include inter alia: Uprooting, felling, cutting or burning; treatment with a weed killer that is registered for use in connection with such plants in accordance with the directions for the use of such a weed killer; biological control carried out in accordance with the stipulations of the APA, the Environment Conservation Act 73 of 1989) and any other applicable legislation; any other method of treatment recognised by the executive officer that has as its object the control of the plants concerned, subject to the provisions of sub-regulation (4); a combination of one or more of the methods prescribed in paragraphs (a), (b), (c), and (d) save that biological control reserves and areas where biological control agents are effective shall not be disturbed by other control methods to the extent that the agents are destroyed or become ineffective. 
of the provisions of the APA to regulate the intentional introduction of AISs as biological control agents in the absence of any substantive provisions provided by CARA.

Although the APA does not specifically refer to biological control agents, it does mandate biological control by allowing for the importation of non-indigenous pathogens or insects for the purposes of combating undesirable plants, pathogens or exotic animals. ${ }^{85}$ The regulatory process for the import and release of biological control agents is administered by DAFF in line with the provisions of the International Plant Protection Convention and the relevant International Standards for the Phytosanitary Measures developed by the Food and Agriculture Organisation (FAO) of the UN. ${ }^{86}$ Before an import permit may be issued, DAFF will require specific information on the target weed, the candidate biological control agent and the envisaged research, as well as a prediction of the potential impacts of the biological control agent on the environment. ${ }^{87}$ Import permits for candidate biological control agents are issued by DAFF subject to the requirements of quarantine being imposed. Once a comprehensive report on the specific agent is available for DAFF to consider, the quarantine may be lifted.88 In terms of the working of the APA, no written protocols exist, other than those provided by the Phytosanitary Measures for the format or contents of the biological release application. It is left to each applicant requesting a permit for the release of a biological control agent to convince the authorities of the desirability and safety of releasing a particular biological control agent.

Section 3(5)(a) Conservation of Agricultural Resources Act 43 of 1983.

Klein et al 2011 African Entomology 490. The International Standards for Phytosanitary Measures also feature in the Draft Alien and Invasive Species Regulations as published under NEM:BA. See note 100 below.

87 Klein et al 2011 African Entomology 490.

88 Klein et al 2011 African Entomology 490. The reports considered by DAFF have also since 1993 been submitted to three independent reviewers versed in the science of biological control so as to obtain further impartial specialist opinion. 
NEM: BA contains several provisions indirectly regulating the use of biological control agents in so far as they are alien or listed invasive species. ${ }^{89}$ NEM:BA imposes several requirements on persons wanting to undertake restricted activities with alien or listed invasive species, as described above. Any person thus wanting to introduce bio-control agents which are deemed to be alien or invasive will thus be subject to these requirements. As stated in the previous section, permits for the import of any alien species, such as biological control agents, must be obtained from DEA. It must be remembered that this permit is required in addition to the permit required under the APA and issued by DAFF. Before issuing the permit, NEM:BA requires that the "correct procedure" be followed. The procedure for risk assessment, of course, is set out in a more substantive manner in the draft alien and invasive species regulations. It is contended by Klein et al that is expected to see the promulgated Alien and Invasive Species Regulations calling for an initial risk assessment before the importation of the biological control agent, with a more comprehensive risk assessment being conducted before its release from quarantine. ${ }^{90}$ The Draft Alien and Invasive Species Regulations provide an insight into the proposed risk assessment procedure for the importation of alien species in the Republic through the workings of regulations 37 and 38 , as discussed above.

89 The main tenets of AIS and AIP regulation are contained within Chapter 5 of NEM:BA, despite the fact that certain indirect provisions contained elsewhere in the Act make indirect provision for the regulation of AISs and AIPs and by implication to the introduction of biological control agents. Some of these provisions include inter alia those relating to biodiversity planning as contained in Chapter 3 part $i$ and ii of NEM:BA. Specifically the provisions of reg 50 come to mind, especially those dealing with research, which state that in subsection (1)The minister must promote research done by the Institute and other institutions on biodiversity conservation including the sustainable use, protection and conservation of indigenous biological resources. In accordance with s 50(2) such research may include research inter alia on threatening processes or activities likely to impact on biodiversity conservation. It may be argued that research into biological control and the release of such biological control agents may be construed to be a threat, and therefore subject to further regulation. Chapter 4, which deals with threatened or protected ecosystems, makes provision for threatening processes in listed ecosystems, whereby the minister may by notice in the Gazette identify any process or activity in a listed ecosystem as a threatening processes. It might be argued that the provision of $s$ 53(1) might apply to the release of biological control agents within a listed ecosystem, such a release being construed to be a potentially threatening process. If the release of a biological control agent in a listed ecosystem were to be regarded as a threatening process it would be necessary for an Environmental Impact Assessment (an EIA) to be conducted in accordance with s 24 National Environmental Management Act 107 of 1998 and the EIA regulations (GN R543-547 in GG 33306 of 18 June 2013). A list of threatened ecosystems has been published by DEA in GNR 1002 in GG 34809 of 9 December 2011. 
Notwithstanding the provisions described above, the current Chapter 8 of the Draft Alien and Invasive Species Regulations deals specifically with biological control and research. Regulation 61 deals specifically with the establishment of biological control reserves. ${ }^{91}$ The department may demarcate an area as a biological control reserve for the breeding of biological control agents. ${ }^{92}$ It may also determine the conditions that it considers necessary to secure the biological control reserve, ${ }^{93}$ and it may notify land users of the demarcation of a reserve and the conditions related to such a demarcation. ${ }^{94}$ Any landowners or users falling within a demarcated biological control reserve shall be obliged to comply with the conditions set for such a reserve and may be held liable for costs should they wilfully hinder the management of the biological control reserve. ${ }^{95}$

Regulation 62 deals with exemptions for research and biological control, and states that despite the provisions of regulations $23,26,27,28,29$ and 31 as described above, the issuing authority may issue a permit to carry out a restricted activity involving a specimen of a prohibited or listed invasive species or to undertake a prescribed activity if the applicant is a scientific institution, ${ }^{96}$ and the specimen will be used for research, ${ }^{97}$ or forms part of a preliminary study into biological control methods or forms part of an effective biological control programme, ${ }^{98}$ or the

91 The draft regulations provide no definition for a biological control reserve, but define biological control as being the use of specimens of one species for the purposes of preying on, parasitising on, damaging, killing or controlling other species.

92 Regulation 61(1)(a) of the Draft Alien and Invasive Species Regulations.

93 Regulation 61(1)(b) of the Draft Alien and Invasive Species Regulations.

94 Regulation 61(1)(c) of the Draft Alien and Invasive Species Regulations.

95 Regulation 61(2) of the Draft Alien and Invasive Species Regulations.

96 Regulation 62(1)(a) of the Draft Alien and Invasive Species Regulations.

97 Regulation 62(1)(b)(i) of the Draft Alien and Invasive Species Regulations. When issuing a permit in accordance with reg 62(1)(b), the issuing authority must determine the restrictions and conditions, including quarantine conditions for the importation of a specimen, and mechanisms for ensuring compliance with conditions for the prevention of escape of specimens.

98 Regulation 62(1)(b)(ii) of the Draft Alien and Invasive Species Regulations. When issuing a permit in terms of reg 62(1)(b)(ii), the issuing authority must determine the restrictions and conditions, including quarantine conditions, for the importation, the release into the wild of a specimen and mechanisms for ensuring compliance with conditions relating to the introduction, research and release of specimens. The issuing authority must apply and comply with the standards as set up by the International Standards for Phytosanitary Measures ISPM 3 (Guidelines for the Export, Shipment, Import and Release of Biological Control Agents and Other Beneficial Organisms) of the International Plant Protection Organisation, to which South Africa is 
restricted activity forms part of a national initiative to eradicate the species. ${ }^{99}$ These provisions thus mandate the issuing authority to allow inter alia for the import, conveyance and release of alien or invasive species, despite the provisions contained elsewhere in the regulations, should the release fall under the auspices of a biological control initiative, subject to the provisions of regulation 62 .

The Draft Regulations serve to provide some insights into the substantive nature of what NEM:BA attempts to achieve through Chapter 5. However, until such time as these regulations are promulgated, the regulation of bio-control agents within NEM:BA will be subject to NEM:BA chapter 5 and the applicable provisions contained therein. The Draft Regulations are commendable in that they provide substantive guidance as to the risk assessments which NEM:BA requires but has failed to address. The regulations pertaining to biological control agents also serve to clear the water in so far as these species are concerned, allowing for a framework within which biological agents can be directly regulated, without the implied or inferred uncertainties arising from a reading of CARA and NEM:BA. The degree to which these regulations are to align to the requirements of DAFF and the workings of the APA and CARA is uncertain, however. Furthermore, until such time as these regulations are promulgated the importation and release of biological control agents will be subject to the regulation of the APA only.

a signatory, relating to the import and release of biological control. The issuing authority must furthermore ensure compliance with the technical advice to the Register of Fertilizers, Farm Feeds, Agricultural Remedies and Stock Remedies Act 36 of 1947 where biological control agents are used inadvertently as bio-pesticides for commercial use. Last the issuing authority must determine mechanisms to ensure compliance with conditions for the prevention of escape by specimens and procedures to be followed in the event of an escape. 


\subsection{Concluding remarks on the challenges relating to the regulation of biological control agents}

This note has attempted to provide a brief overview of the two main legislative mechanisms regulating the use of bio-control agents in South Africa. Although the authors recognise the wider legal framework applicable to alien and invasive species, and by implication biological control agents, the note has focused specifically on the provisions of CARA, the APA, NEM:BA and the still Draft Alien and Invasive Species Regulations, in an attempt to distil the more pertinent regulatory provisions relating to the use of biological control agents. In the absence of the substantive provisions to be provided by the Draft Regulations, once they are promulgated, any prospective user of biological control agents will be subject to the workings of CARA and its relevant regulations pertaining to alien and invasive species, the APA, and chapter 5 of NEM:BA. Apart from the APA, these provisions provide no substantive guidance as to how biological control agents should be controlled, but provide indirect guidance through the regulations pertaining to the categories of alien and invasive species and the exclusions allowed for bio control reserves. Although the APA does contain more detail, the lack of a written protocol as to what exactly is required to be proven in each case presented for a specific biological control agent may be grounds for inconsistency in the consideration and approval of such applications. The NEM:BA provides for several indirect provisions relating to biological control agents, but these provisions lack the regulatory substance that is required, a situation that will remain until the promulgation of the Draft Alien and Invasive Species Regulations. With respect to biological control agents, the Draft Regulations do in fact contain several pertinent provisions relating to biological control agents through the workings of regulations 61 and 62, allowing for the permitting of such biological control agents in so far as restricted activities are undertaken, despite the provisions contained elsewhere in the Regulations. Furthermore it is not clear from the Draft Regulations as to how the CARA, the APA and NEM:BA will be aligned with regards to the control of alien and invasive species. It can only be hoped that the 'new' alien and invasive 
species regulations to be published will address this issue in more detail. ${ }^{100}$ Despite the historic progressions pertaining to the authorisation of the release of biological control agents and the lessons gleaned therefrom, ${ }^{101}$ a fragmented system of authorisation is still in place, with any prospective release of biological control agents being subject to authorisation from both DAFF and the DEA, under the auspices of the APA and NEM:BA respectively.

If the introduction or spread of alien and invasive plants can be curtailed by biological control agents that do not cause harm to the environment or ecosystems, they may actually be regarded as providing an ecosystem service. The introduction of any such biological control agent will, however, have to be strictly regulated.

\footnotetext{
100 Seen 47 above.

101 The note has for the sake of brevity not touched on the historic development of the licensing of the release of biological control agents as contained in the Environmental Conservation Act 73 of 1989 and the National Environmental Management Act 107 of 1998. For a concise discussion of these developments and the accompanying challenges, refer to Klein et al 2011 African Entomology 489-497.
} 


\section{Bibliography}

Brooks et al 2004 BioScience

Brooks ML et al "Effects of Invasive Alien Plants on Fire Regimes" 2004 BioScience 677-688

Department of Environmental Affairs and Tourism National Biodiversity Strategy

Department of Environmental Affairs and Tourism National Biodiversity Strategy and Action Plan (Department of Environmental Affairs and Tourism Pretoria 2005)

Driver et al National Biodiversity Assessment 2011

Driver A et al National Biodiversity Assessment 2011: An Assessment of South Africa's Biodiversity and Ecosystems - Synthesis Report (South African National Biodiversity Institute and Department of Environmental Affairs Pretoria 2012)

Ecological Society of America 1997 Spring

Ecological Society of America "Ecosystem Services: Benefits" 1997 Spring 118

Egoh et a/ 2012 Ecosystem Services

Egoh BN et al "An African Account of Ecosystem Services Provision: Use, Threats and Options for Sustainable Livelihoods" 2012 Ecosystem Services 7181

Klein et a/ 2011 African Entomology

Klein $\mathrm{H}$ et al "Regulation and Risk Assessment for the Importations and Release of Biological Control Agents against Invasive Alien Plants in South Africa" 2011 African Entomology 489-497 
Le Maitre, O'Farrell and Reyers 2007 SAJS

Le Maitre DC, O'Farrell PJ and Reyers B "Ecosystem Services in South Africa: A Research Theme that can Engage Environmental, Economic and Social Scientists in the Development of Sustainability Science? " 2007 SAJS 367-376

McNeely "Invasive Species"

McNeely J "Invasive Species: A Costly Catastrophe for Native Biodiversity" in Preston G, Brown AG and Van Wyk E (eds) Best Management Practices for Preventing and Controlling Invasive Alien Species Symposium 22-24 February 2000 Cape Town 1-10

Moran, Hoffmann and Zimmerman 2005 Frontiers of Ecology and Environment Moran C, Hoffmann JH and Zimmerman G "Biological Control of Invasive Plants in South Africa: Necessity, Circumspection, and Success" 2005 Frontiers of Ecology and Environment 77-83

Olckers 1999 African Entomology Memoir

Olckers T "Introduction: Biological Control of Weeds in South Africa (1990 1998) " 1999 African Entomology Memoir No 1

Olivier, Myakayaka and Richards "Indigenous Plants"

Olivier NJJ, Myakayaka AG and Richards RL "Indigenous Plants" in Strydom HA and King ND (eds) Fuggle and Rabie's Environmental Management in South Africa (Juta Cape Town 2009) 342-392

Parry-Davies Enviropedia

Parry-Davies D The Enviropedia (Ecological Publishing Simonstown 2012)

Paterson 2006 PER

Paterson AR "Clearing a Path Towards Effective Alien Invasive Control: The Legal Conundrum" 2006 PER 152-207 
Simberloff and Stiling 1996 Biological Conservation

Simberloff D and Stiling P "Risks of Species Introduced for Biological Control" 1996 Biological Conservation 185-192

Van Wilgen et al "Preliminary Assessment"

Van Wilgen BW et al "A Preliminary Assessment of the Impacts of Invasive

Alien Plants on Ecosystem Services in South Africa" in Weed Management Society of South Australia 15th Australian Weeds Conference 24-28 September 2006 Adelaide 819-822

Zimmerman and Moran 1991 Agriculture, Ecosystems and Environment

Zimmerman G and Moran C "Biological Control of Prickly Pear, Opuntia Ficuusindica (Cactaceae), in South Africa" 1991 Agriculture, Ecosystems and Environment 29-35

\section{Register of legislation}

Agricultural Pests Act 43 of 1983

Conservation of Agricultural Resources Act 43 of 1983

Conservation of Agricultural Resources Regulations in GNR 1048 in GG 9238 of 25

May 1984

Draft Alien and Invasive Species Regulation in GNR 247 in GG 32090 of 3 April 2009

Draft National List of Alien Species in GNR 248 in GG 32090 of 3 April 2009

Draft National List of Invasive Species in GNR 250 in GG 32090 of 3 April 2009

Draft National List of Prohibited Alien Species in GNR 249 in GG 32090 of 3 April 2009

Environmental Conservation Act 73 of 1989

Environmental Impact Assessment Regulations GN R543-547 in GG 33306 of 18 June 2013

List of Threatened Ecosystems in GNR 1002 in GG 34809 of 9 December 2011 National Biodiversity Framework in GNR 813 in GG 32474 of 3 August 2009 National Environmental Management Act 107 of 1998 
National Environmental Management: Biodiversity Act 10 of 2004

National Water Act 36 of 1998

Register of Fertilizers, Farm Feeds, Agricultural Remedies and Stock Remedies Act 36 of 1947

\section{Register of internet sources}

Anonymous Date Unknown www.unep.org

Anonymous Date Unknown Working for Water: A South African Sustainability

Case www.unep.org/training/programmes/.../Part_3/.../WfW_case.pdf_[date of use 27 Feb 2013]

Department of Water Affairs 2013 www.dwaf.gov.za

Department of Water Affairs 2013 WfW Position Paper on Biocontrol www.dwaf.gov.za/wfw/Control/docs/article1.2.pdf [date of use 21 Feb 2013]

European Commission 2009 ec.europa.eu

European Commission 2009 Ecosystem Goods and Services ec.europa.eu/environment/nature/info/pubs/docs/ecosystem.pdf [date of use 21 Feb 2013]

ICT Update 2005 ictupdate.cta.int

ICT Update 2005 A Current Awareness Bulletin for ACP Agriculture: CTA Invasive Species ictupdate.cta.int/content/download/564/27291/file/ 24_EN.pdf [date of use 21 Feb 2013]

Martin and Foxcroft 2001 www.sanparks.org.za

Martin BW and Foxcroft LC 2001 Catalogue of Biological Control Interventions on Invasive Alien Plants: Kruger National Park www.sanparks.org.za/docs/parks_kruger/conservation/scientific/ff/alien_biota /reports/Internal-report-biocontrol.pdf [date of use 27 Feb 2013] 
The Water Page 2012 www.thewaterpage.com

The Water Page 2012 Invasive Alien Plants www.thewaterpage.com /invasive_aliens.htm [date of use 6 Jun 2013]

UN 1992 www.cbd.int

United Nations 1992 Convention on Biological Diversity www.cbd.int /doc/legal/cbd-en.pdf [date of use $27 \mathrm{Feb}$ 2013]

UNEP Finance Initiative 2008 www.unepfi.org

United Nations Environmental Program Finance Initiative 2008 Biodiversity and Ecosystem Services: Bloom or Bust? www.unepfi.org/ fileadmin/documents/bloom_or_bust_report.pdf [date of use 27 Feb 2013]

\section{List of abbreviations}

$\begin{array}{ll}\text { AIP } & \text { Alien and Invasive Plants } \\ \text { AIS } & \text { Alien and Invasive Species } \\ \text { APA } & \text { Agricultural Pests Act } \\ \text { CARA } & \text { Conservation of Agricultural Resources Act } \\ \text { DAFF } & \text { Department of Agriculture, Forestry and Fisheries } \\ \text { DEA } & \text { Department of Environmental Affairs } \\ \text { EIA } & \text { Environmental Impact Assessment } \\ \text { NEM:BA } & \text { National Environmental Management: Biodiversity Act } \\ \text { PER } & \text { Potchefstroomse Elektroniese Regstydskrif } \\ \text { SAJS } & \text { South African Journal of Science } \\ \text { UN } & \text { United Nations } \\ \text { UNEP } & \text { United Nations Environmental Program }\end{array}$

